\title{
Consumers' attitude and opinion towards different types of fresh cheese: an exploratory study
}

\author{
Cássia Pereira de BARROS ${ }^{1}$, Amauri ROSENTHAL ${ }^{2}$, Eduardo Henrique Miranda WALTER ${ }^{2}$, Rosires DELIZA
}

\begin{abstract}
Fresh cheese stands out for its tradition and widespread consumption in Brazil. However, there is a lack of information on motivation towards the consumption of available fresh cheeses in the Brazilian market. Focus group sessions were used to explore consumers' attitude and opinion about fresh cheese. Products with different characteristics were used to stimulate discussion among participants including cheese with "no added salt", the claim "contains probiotic microorganisms" and products processed with goat milk. The salt content played an important role on the consumer intention to purchase of fresh cheese. Participants stated that they would consume cheese without salt only by following a medical prescription. However, the subjects declared that they would buy reduced salt cheese if such reduction would not compromise the flavor. The meaning of the claim "contains probiotic microorganisms" was often declared as unknown during the discussion. However, they would buy a probiotic product. In addition, it was mentioned that a premium price would be paid for such functional cheese. Participants declared that would buy goat cheese. Nevertheless, to pay a higher price over the conventional one was a controversial and debatable issue among consumers. Results revealed important implications for the development of marketing strategies for fresh cheese.
\end{abstract}

Keywords: consumer; Focus group; fresh cheese; labelling; packaging.

Practical Application: The salt content played an important role on the consumer intention to purchase of fresh cheese. They would buy a probiotic product. Participants declared that would buy goat cheese. However, to pay more for the goat cheese over the conventional one was a debatable issue.

\section{Introduction}

During the development of food products, companies should make efforts to understand consumer preferences as well as the perception of sensory and non-sensory characteristics in order to assure product success in the market (Moskowitz \& Hartmann, 2008; Tuorila \& Monteleone, 2009). The sensory characteristics of a product are not enough to meet consumer requirements in the context of today's highly competitive and fast moving markets (Enneking et al., 2007). There are several non-sensory factors, such as packaging/ labelling and the information contained therein (e.g. processing technology, price, nutritional information) or attitudes and beliefs (such as convenience, health properties) that play an important role on consumer food choice and liking (Costell et al., 2010; Jaeger, 2006; Lee et al., 2015; Torres-Moreno et al., 2012). Several studies have shown that packaging and labelling are important factors that affect consumer product perception and intention to purchase (Abadio-Finco et al., 2010; Carneiro et al., 2005; Deliza \& MacFie, 1996; Enneking et al., 2007; Gatti et al., 2014; Lagerkvist, 2013). In this context, it is important to identify which are the package features that are relevant to consumers, and which is the information they expect to find in a label.

Minas fresh cheese is a popular product in Brazil. It is widely appreciated in the country and it occupies the fourth position in the national cheese market (Scot Consultoria, 2010).
Minas fresh cheese is part of the Brazilian eating habits, having high sensory acceptability and affordable prices to the population; therefore, people from all social classes consume it. In spite of such popularity, few studies regarding the consumer behavior towards Minas fresh cheese are found in the literature. On the other hand, the consumption of fresh goat cheese and probiotic fresh cheese is still rare; thus, the investigation on how they are perceived by consumers may help introducing a nutritious, functional and different product option into the market.

Qualitative research has been a valuable tool to investigate consumer product perception, making it possible to obtain detailed information on attitudes, opinions, and habits of participants (Hashim et al., 1996). Among the qualitative methods is Focus group, which is defined as a way to interview in a carefully planned manner, to obtain individual opinions of a group of people on a particular area of interest. Because of the exploratory character, Focus group sessions have been fairly applied when little is known about the subject (Deliza et al., 2003), also allowing the identification of the relevant features of a particular product that affect consumers' choice; or discuss new product concepts and raise important attributes of the product packaging (van Kleef et al., 2005). Several studies have been reported using such as methodology. Krause et al. (2007) conducted two Focus group sessions with 16 butter consumers 
to gain an understanding of consumer use and consumption habits. Bouteille et al. (2013) explored the freshness sensation of yoghurts and yoghurt-like products by means of two Focus group sessions $(n=19)$. Focus group was used by Lahne \& Trubek (2014) to explain consumer preference for Vermont artisan cheese and the relationship between that preference and sensory experience. The present study aimed to explore consumers' attitude, opinion and belief regarding fresh cheese, and identify the relevant packaging factors affecting consumers' product perception of different types of fresh cheese, by applying Focus group.

\section{Material and methods}

\subsection{Consumers}

The study was approved by the Human Research Ethics Committee - University Veiga of Almeida, process $n$. 19198613.5.0000.5291.

Consumers who like and consume cheese at least twice a week, and participate in the dwelling food shopping were invited to take part in the Focus group sessions. Thirty subjects were recruited and 22 attended the sessions. The first Focus group session consisted of five women and three men; they worked at the restaurant and the cleaning sector of Embrapa (Brazilian Agricultural Research Corporation) Food Technology, Rio de Janeiro, Brazil. The second session had five women and two men. They worked at the administrative side of the referred institution. Four women and three men took part in the third group; all of them were Embrapa's trainees. Within each session, participants had similar age and education level, allowing a homogeneous group of people, and favoring discussion.

\subsection{Conduction of the Focus group sessions}

The three Focus group sessions were conducted following the recommendations of Casey \& Krueger (1994). At the beginning of each session, the moderator explained the purpose of the study and the participants introduced themselves to the group. Participants' demographic data, as well as buying habits and cheese consumption information were collected at the beginning of each session using specific questionnaire. Then, they read and signed the consent form. All participants volunteered to participate in the study and received no monetary incentive.

The sessions were held in a room with the capacity to comfortably accommodate consumers. They sat around a round table to allow interaction, eye contact and harmony in the discussion. The interview guide has been carefully planned, followed in all sessions and aimed to provoke discussion on the following topics: food intake related to products with health claims, consumption/understanding of probiotics, consumption of foods without salt and with reduced salt content, factors that may contribute to consume these foods, and factors that hinder this consumption. The sessions were conducted by the same moderator, tape recorded and registered by an assistant. Table 1 shows the interview guide.

We started the discussion with general questions about the opinion of consumers and their attitudes toward labels of the products they consume. The first questions of the Focus group sessions usually have the aim at warming up the debate among participants, followed by the key issues. The last questions are more related to the desired information. Some other questions were eventually asked for further clarification of opinions, depending on the dynamics of each group.

The package of six brands of fresh cheese (made from cow and goat milk), described in Table 2 and purchased in supermarkets in Rio de Janeiro and São Paulo (both Brazilian cities) were presented to participants one by one. The order of packages presentation was different in each session, which lasted from 60 to 80 minutes. Participants were assured that there were no right or wrong answers to the questions addressed, and were encouraged to express their views in a sincere manner, even if they were different from the other group members.

Table 1. Interview guide for the Focus group sessions.

\footnotetext{
1. Do you observe the labels of the products you consume often?

2. What do you notice on them?

3. What else catches your attention?

4. What did you think of the package?

5. What do you consider important in this package?

6. Would like to see some other information and/or illustration displayed on the label?

7. In your opinion, what are the negative features of this package?

8. Which are the positive features of this package?

9. While observing the package of a product, which factors influences your purchase intentions?

10. The information on the label: "Contains no salt" is important to you? Would you buy a product with such information?

11. How much more would you pay for this product compared to the price of the conventional one?

12. The information on the label: "reduced salt content" is important to you? Would you buy a product with such information?

13. How much would you pay over for this product in relation to the price of conventional one?

14. How do you understand the expression "contains probiotic microorganisms"?

15. How do you think we can inform, in the label, that a product is probiotic?

16. If you read on the label the piece of information: "Contains probiotic microorganisms", would you buy?

17. How much would you pay over for this product in relation to the price of conventional one?
} 
Table 2. Products used in conducting the Focus group sessions.

\begin{tabular}{cl}
\hline Product & \multicolumn{1}{c}{ Description } \\
\hline 1 & $\begin{array}{l}\text { Fresh goat cheese. Front label with the following information: fresh goat cheese, brand, package weight: } 4 \mathrm{~g}, \\
\text { must be weighed in the presence of the consumer, consume within } 5 \text { days after opening, does not contain } \\
\text { gluten, Brazilian industry; inspection seal SIS (State Inspection Service). }\end{array}$ \\
\hline
\end{tabular}

Fresh goat cheese. Front label with the following information in red: brand and goat cheese in the English and French languages. Back label in white color and written in black, in several languages, nutrition facts, weight $113 \mathrm{~g}$, produced in France; damaged paper label with the same information in Portuguese, with hampered visualization.

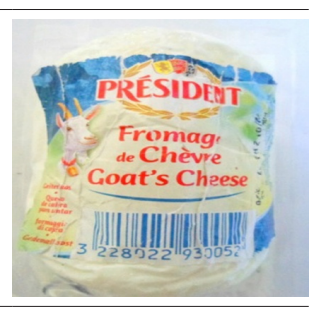

Minas fresh cheese. Information on top: Minas fresh cheese without salt, you are acquiring a fresh product without preservatives, must be weighed in the presence of the consumer, consume within 7 days after opening, package weight $18 \mathrm{~g}$, contains no gluten, brand name, Brazilian industry; inspection seal SIS.

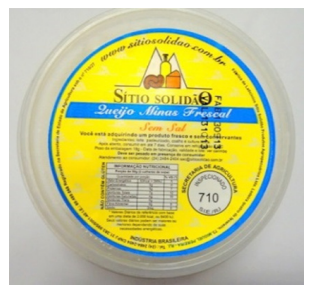

Ultra filtered fresh cheese. Top and sides with the following information: ultra filtered fresh cheese; Bifidobacterium animalis contributes to the balance of intestinal flora. Consumption must be associated with a balanced diet and healthy lifestyle; the left corner, with small print, the following information: contains from $10^{8}$ to $10^{12}$ colony forming units (CFU) of Bifidobacterium animalis per $50 \mathrm{~g}$; Brazilian industry, weight $250 \mathrm{~g}$. Bottom panel with inspection seal SIF (Federal or Country Inspection Service) and text: consume within 5 days from opening, contains no gluten.

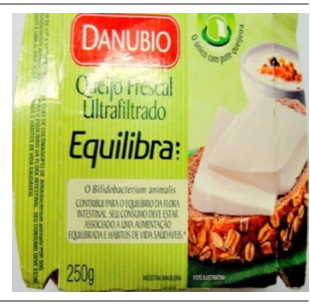

Fresh Minas cheese. with probiotic information. At the top, highlighted, the following information: brand, Biofrescal, fresh Minas cheese contains probiotic microorganisms, and arranged around the label in very small letters: does not contain gluten; Bifidobacterium lactis (probiotic) contributes to the balance of intestinal flora. Consumption must be associated with a balanced diet and a healthy lifestyle; Contains more than 108 colony forming units (CFU) of Bifidobacterium lactis per portion of 30 g. Suggested intake: minimum of $30 \mathrm{~g}$ ( 1 slice) per day. Inspection seal SIF printed in the frontal panel.

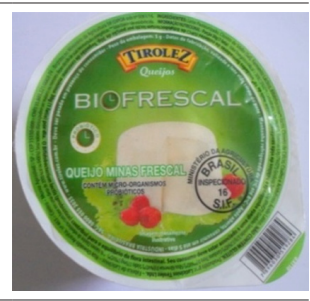

Fresh Minas cheese. Front label with the information: brand, fresh Minas cheese, Sanbios, contains probiotic microorganisms; Bifidobacterium lactis (probiotic) contributes to the balance of intestinal flora. Consumption must be associated with a balanced diet and a healthy lifestyle; 1 slice $=17 \%$ of the recommended daily dose of calcium! \% DV*, must be weighed in the presence of the consumer, Brazilian industry. Back label with inspection seal SIF and ISO 9001 quality stamps. In green color, the following information: Suggested intake: minimum $30 \mathrm{~g}$ ( 1 slice) per day. Each $30 \mathrm{~g}$ contains more than $10^{8}$ colony forming units (CFU) of Bifidobacterium lactis; consume within 5 days from opening, weight of the package, does not contain gluten.

\subsection{Data treatment}

All data obtained (through questionnaires and response notes) were analyzed considering the words used by consumers, the context of the question and the specificity of the responses, with no statistical analysis due to the qualitative nature of the study. Percentages were used to illustrate the results in an alternative manner (Dantas et al., 2004).

\section{Results and discussion}

The demographic information about the participants of the three Focus group sessions is shown in Table 3. Most participants from the three Focus group sessions were female (63.6\%) and $77.3 \%$ with age between 20 and 49 years old. Regarding the education level of participants, $27.3 \%$ were post graduated, $31.8 \%$ graduate, $36.4 \%$ had high school and $4.5 \%$ had only 
Table 3. Participants' characteristics of the Focus group sessions.

\begin{tabular}{lccc}
\hline \multicolumn{1}{c}{ Characteristics } & \multicolumn{3}{c}{ Frequency (\%) } \\
\cline { 2 - 4 } & $\begin{array}{c}\text { Session } 1 \\
(\mathrm{n}=8)\end{array}$ & $\begin{array}{c}\text { Session } 2 \\
(\mathrm{n}=7)\end{array}$ & $\begin{array}{c}\text { Session } 3 \\
(\mathrm{n}=7)\end{array}$ \\
\hline Gender & & & \\
$\quad$ Male & 37.5 & 28.6 & 42.9 \\
$\quad$ Female & 62.5 & 71.4 & 57.1 \\
Age (years) & & & \\
18-29 & 0 & 0 & 100 \\
30-39 & 0 & 28.6 & 0 \\
40-49 & 75 & 57.1 & 0 \\
$50-59$ & 25 & 14.3 & 0 \\
60-69 & 0 & 0 & 0 \\
Education level & & & \\
Fundamental & 12.5 & 0 & 0 \\
High school & 62.5 & 14.3 & 28.6 \\
Graduate degree & 25 & 14.3 & 57.1 \\
Post Graduate degree & 0 & 71.4 & 14.3 \\
Monthly family income & & & \\
(Brazilian minimal wages $\left.{ }^{*}\right)$ & & & \\
1 a 5 & 87.5 & 0 & 57.1 \\
5 a 10 & 12.5 & 28.6 & 42.9 \\
10 a 20 & 0 & 28.6 & 0 \\
$>$ 20 & 0 & 42.8 & 0 \\
\hline
\end{tabular}

${ }^{\star}$ Brazilian minimal wages (2014) $=\mathrm{R} \$ 724,00$.

fundamental education. Regarding monthly family income, $50 \%$ received between one and five minimum Brazilian wages; $27.3 \%$ between five and ten minimum wages and $22.7 \%$ received above ten salaries.

Regarding the frequency of cheese consumption, $63.6 \%$ of participants from the three Focus group sessions reported consuming it frequently at least once a week, and $36.4 \%$ consumed it daily. Figure 1 illustrates the frequency of reading food labels, among participants. It was found that $36.4 \%$ of them always read the labels of the products they consume; $31.8 \%$ read it often and $31.8 \% \mathrm{~s}$ declared to read labels once in a while. They informed the expiration date (95.5\%), price (77.3\%), brand (68.1\%) and information on ingredients (50\%) as the main features observed in the labels of foods and beverages they consume (Figure 2). During the sessions, some subjects have added net weight and origin as characteristics also observed in the cheese label. When asked about the characteristics of the food and the label that caught more attention to them at the time of purchase, the most cited were appearance, expiration date and nutritional information facts (Figure 3 ).

The price was important but not a priority for participants of the second and third sessions; and, if the difference were not significant, they would pay more for a higher quality product. It is noteworthy that most of these participants reported having monthly family income above five minimum wages.

The majority stated that the appearance of the product is very important, being one of the first criteria in the process of purchase decision. Similar results were reported by Soares et al. (2008) and Barreto et al. (2012). The brand had a great influence

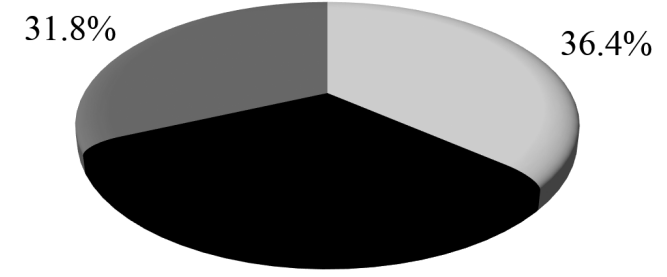

$31.8 \%$

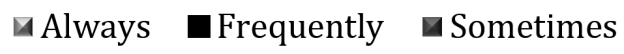

Figure 1. Frequency of reading product labels by participants of the Focus group sessions.

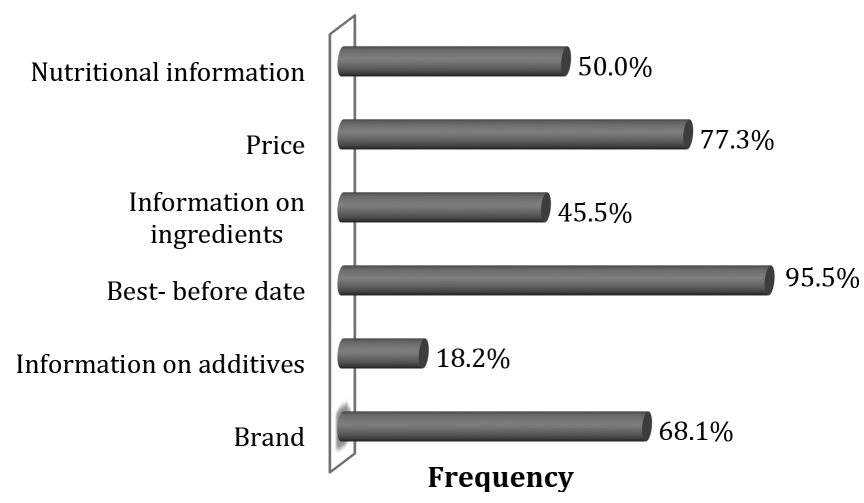

Figure 2. Main characteristics observed in food labels by Focus group participants.

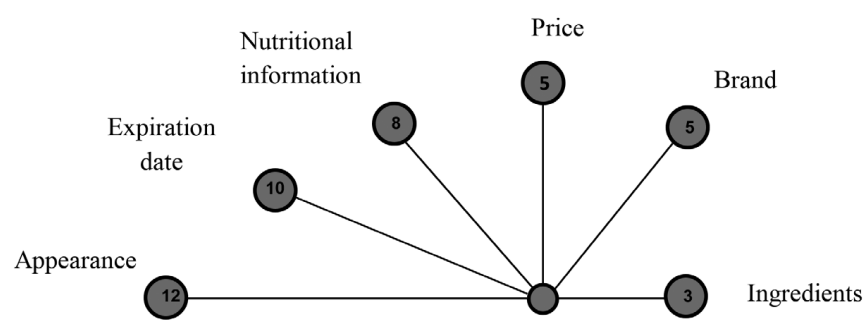

Figure 3. Number of times, expressed inside the grey area, showing the main food and label characteristics that caught consumers' attention at the time of purchase.

on intention to purchase for some participants, implying confidence and safety for them, as well as helping them knowing what to expect from the product they take home. A similar result was reached in other studies (Annunziata \& Vecchio, 2013; Ares et al., 2010) regarding non-sensory attributes, where the brand was the key factor influencing consumer's choice when purchasing functional foods. However, the brand did not have a strong effect on product perception in the present study with fresh cheese, since few participants said they would not buy an unknown brand product.

The participants also declared that the appearance of the package (colors, design and size of the information) is an important factor to draw the consumer's attention, especially when the 
brand is unknown. Bialkova \& van Trijp (2010) reported that the color scheme, size, familiarity with the label and its location in front of the package were the main determinants of consumer attention. Table 4 presents a summary of the most frequent responses in the three Focus group sessions.

Participants who were more concerned about nutritional information and ingredients information belonged to the second and third groups. In nutrition facts, they sought information primarily on sodium and other mentioned types of fat (trans, saturated, polyunsaturated), carbohydrate and energy value.
Regarding information on ingredients, they declared seeking the presence of gluten, due to ingestion restriction. In the first session, only one participant informed being searching for such information. Other participants seemed to observe mainly the appearance of the product, expiration date, price and brand. Some participants in the first group said that the salt content of the cheese was very important when purchasing cheese. This result can be explained by the campaigns and dissemination of information about the importance of reducing the salt ingestion for the prevention of chronic diseases such as hypertension and

Table 4. Main comments made by participants during the three Focus group sessions.

Label: I liked the package; These red and blue colours made it different from all others.
Illustration: Draws attention and the coat of arms gives an idea of tradition.
Price: I would only pay more, if I tried and liked it.
Brand: Unknown, was not considered negative point
Information: Complete, visible and well distributed.

Label: Paper label on a product that must be kept refrigerated, it is controversial. Could be a plastic label. Illustration: I liked more the other goat picture.

Price: I would not pay more.

Brand: Well-known brand; it has influence in the product purchase.

Information: Written in foreign language, I cannot read it, the text size is too small, too much information.

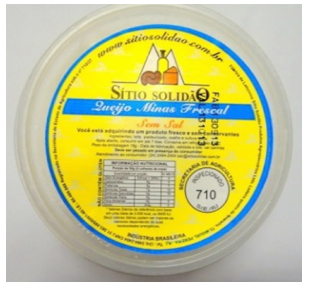

Label: Resistant package, it provides greater integrity of the cheese.

Illustration: I did not like the pictures. It is too awkward.

Price: I would not pay more because it contains no salt, only if I had too.

Brand: Unknown brand; I would not buy because I do not know the brand.

Information: Contains no salt, looks like ricotta, and seems to have no flavour. The information "no food preservatives"

counted positively to me.

LANUBi0
Label: The package hides the product, cannot take a good look at the product, had to look through the sides.
Illustration: Tries to imply the message of being (a) healthy (product), showing a picture of whole wheat bread and yogurt
with granola.
Price: I would pay more for the novelty
Brand: Well-known brand, it influences the product purchase because consumers trust in the brand.
Information: Provides no information regarding what the ultra filtration process is; it is not clear that it is a probiotic
product.

Label: The package of the product seems to be fragile.
Illustration: I could not catch the meaning of the mulberry picture; The clock is a reference to the biological clock.
Price: I would not pay more because I did not like the package.
Brand: Not known by all participants, it hasn't represented a negative aspect.
Information: Not easily seen, the text size is too small.

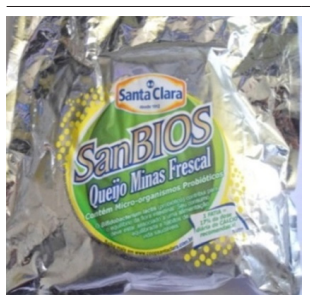

Label: The package is opaque, cannot see if the cheese is deteriorated or not.

Illustration: There could be a picture of a cheese, at least.

Price: I would not pay more because I did not like the package. I cannot see the cheese.

Brand: Not known by all participants, it has not represented a negative aspect.

Information: Clear and well-arranged information. The best label among those presented. 
cardiovascular disease advertised in several countries, including Brazil (Campbell et al., 2011; McLean et al., 2012; Wyness et al., 2012). When asked how they assessed the salt content at the time of purchasing, they said they ask the clerk working at the supermarket's dairy session.

During the evaluation of product 1, after checking that it was goat cheese, participants were asked whether they would buy the product. Few people (participants from session 2) would not buy specifically the product 5 because they did either not like the package, but most of them said they would buy fresh goat cheese, by already having consumed it or because they were curious to try it. However, only few participants would be willing to pay more for the goat cheese over the conventional product processed from cow's milk. However, they would buy it sporadically, although never replacing fresh Minas cheese in the diet. Some participants said they would not pay more for fresh goat cheese without tasting it before, i.e. only if they tried it and liked it they would buy the cheese. "There should be goat cheese tasting in supermarkets, just as there are for other products, for wider dissemination of the product for potential consumers, and encouragement for people who have never tried it before, to purchase the goat cheese", suggested one participant (Man, 18 years old), who was supported by several others.

Participants considered positive the "no salt" statement on the label. However, only one consumer out of the 22 individuals who participated in the study said he would buy cheese without salt as a preventive measure due to family history of hypertension. Everyone else would buy it only in case of medical recommendation. Some quotes from participants in session 1 include "To tell you the truth, I like healthy stuff, but no salt at all, I can't take it" (Woman, 41 years old); "Only if the doctor said to me, you must not ingest salt, you have a high blood pressure condition, you must eat without salt, then yes, I would do it. Otherwise, it's like I'm having ricotta, it is tasteless" (Woman, 45 years old). In the case of cheese with reduced salt content, many participants (all of the first and third sessions) would buy it due to the health benefits but not completely without salt, i.e., they were not keen on compromising the flavor in favour of the health. Several of them would be willing to pay more for products with reduced salt content compared to the conventional product counterparts.

Deliza et al. (2003) showed that consumers infer the flavor of the product from the label, revealing that many package attributes affected the perception and expectation regarding the product. It should be emphasized, however, that the results of several studies suggested that consumers are not willing to compromise taste for possible health benefits (Tuorila \& Cardello, 2002; Verbeke, 2006).

Although the technology used in the cheese preservation process has not been mentioned in the interview guide, it was an attribute that caught the attention of consumers, especially after the presentation of the product 4 (Ultra filtered Fresh Cheese). Participants were unaware of that technology. According to one of them Ultra filtrated; "I do not know what advantage it brings along. This factor can be a huge disadvantage. What does that mean to the consumer?" (Man, 54 years old), another participant: "When the manufacturer says that the product is a fresh ultra-filtered cheese, he should explain to the consumer what that means" (Woman, 37 years old). Therefore, individuals who participated in the Focus group sessions were favorable to the presence of additional information on food packages regarding the applied technology.

In relation to the understanding of the term "contains probiotic microorganisms" participants reported, in general, as "probiotics help regulate intestinal flora" or "assist in the proper functioning of the intestine". This study revealed, however, that some participants (all from first session) were unaware of the term. However, it is noteworthy that these consumers had only finished high school. Annunziata \& Vecchio (2013) investigated the level of knowledge of Italian consumers about probiotic products and the frequency of purchasing them. The results revealed that the Italians are not well informed on the concept of functional foods, mistaking them for diet products or incorrectly associated as food for individuals with health problems. The authors reported that $18 \%$ of respondents said they had never consumed these products mainly because they ignore their properties or doubt about their potential benefits. However, as in the present study, the majority of respondents considered functional foods as products that improve the biological function of the body. The participants with complete high school degree (second session) who were familiar with the term, informed knowing it through the advertisements of yogurt on television: "I understand it only because I see it on television" (Woman, 20 years old). According to Soares et al. (2008) the different media types play a strong role on food choice and consumption and when properly used provide guidelines for a healthy diet.

When asked about the best way to inform consumer that a product "contains probiotic microorganisms", they said it would be stating that the product "contains probiotic microorganisms" followed by the information on their functions without the need to put the scientific name of the microorganism, unless it was a legal requirement. They considered the presence of the name could cause a feeling of awkwardness to the consumer. Likewise, Ares et al. (2009) stated that the use of scientific names could have a negative impact on consumers, and suggested just declaring them if they come together with a health claim on the label, in order to promote a positive association in the consumers' minds between the ingredient and its health effects.

All participants agreed that the product 4 reported more objectively be a probiotic cheese, due to the expression "contains probiotic microorganisms" and their functions to our health presented on the front label. Similar result was reported by Carrilo et al. (2012). The authors showed that consumers were strongly influenced by highlighted claims (color and size) in the front of the package. Participants in the session 3 of the present study suggested the use of graphics (e.g. fibers, "picture of a belly with the down arrow" - used in packs of yogurts and dairy beverages) instead of text for helping consumer's understanding of the nutritional product advantages. It was quoted "Brazilian people do not have the habit of reading, therefore we pay more attention to the image displayed on the product than the text written on it" (Man, 18 years old). Similar result was found by Ares et al. (2010) while investigating the influence of different package attributes on consumers' willingness to buy regular 
and functional chocolate dairy desserts. The presence of the image on the label was one of the variables with higher relative importance, confirming the important role of the package on consumer perception and, therefore, on the intention to purchase of functional foods.

All participants declared that they would buy probiotic products. One person said he would only buy it if he had to, regarding functionality it may have, even if it were more expensive than the conventional one (Man, 54 years old). However, two participants said they preferred having probiotic yogurt instead of probiotic cheese, revealing the importance of the product convenience. Previous studies had already pointed out the high level of acceptance of yogurt as a functional food (Annunziata \& Vecchio, 2013; Hailu et al., 2009; Siegriest et al., 2008; van Kleef et al., 2005; van Trijp \& van Der Lans, 2007). Consumers may associate this type of product with a positive health image and, additionally, the product has already being marketed in Brazil as functional food by some commercial brands. They also mentioned to be much easier drinking a yogurt than making a sandwich with cheese, suggesting that the acceptance of an innovation was also associated with convenience. Urala \& Lähteenmäki (2003) indicated that convenience was an important factor in determining the choice of consumers for functional foods. Considering the time constraints, consumers would probably not be willing to compromise convenience in favor of health related issues, suggesting that functional foods should be developed keeping the same convenience level of its conventional counterpart (Ares, 2011). Urala \& Lähteenmäki (2007) reported that gender and age had no significant influence on consumer interest in functional foods in Finland.

Almost all participants would pay more for a probiotic cheese, some of them due to the curiosity and others for the functionality and health claims. van Kleef et al. (2005) reported that the attractiveness of the health claim positively influenced the intention of consumers to try functional foods, and similarly Urala \& Lähteenmäki (2007) observed that the perceived reward was the strongest attractiveness that affected the willingness to buy functional foods.

\section{Conclusion}

The factors of package / label identified as the most important for consumers when evaluating fresh cheeses were salt content, type of milk used in the cheese production, probiotic, additional information about the technology used in the cheese processing, and the price. Focus group was a useful tool in exploring consumers' attitudes and opinions towards fresh cheese and gathering factors on the package/ label considered important for them. Such factors can be used in subsequent quantitative studies to evaluate the relative importance on the consumer intention to purchase of fresh cheese. Further research is required, with both a qualitative and a quantitative focus, taking into account a more representative sampling of the Brazilian population.

The results of this exploratory study identified that consumers are interested in health claims to be aware of the food benefits, and to help choosing healthier products. Moreover, they are more likely to prefer the label with more concise information and visual appeal for a better understanding of the message. These achievements suggest important implications for the development of effective marketing strategies, which can help increase the competitiveness of this product in the market.

\section{Acknowledgements}

The authors would like to thank the volunteers who participated in the study. They also thank CAPES (Brazilian Ministry of Education), EMBRAPA (Brazilian Agricultural Research Corporation) and FAPERJ (Foundation for Research Support of the State of Rio de Janeiro) for the financial support.

\section{References}

Abadio-Finco, F., Deliza, R., Rosenthal, A., \& Silva, C. H. O. (2010). The effect of extrinsic product attributes of pineapple juice on consumer intention to purchase. Journal of International Food \& Agribusiness Marketing, 22(1-2), 125-142. http://dx.doi. org/10.1080/08974430903372963.

Annunziata, A., \& Vecchio, R. (2013). Consumer perception of functional foods: a conjoint analysis with probiotics. Food Quality and Preference, 28(1), 338-355. http://dx.doi.org/10.1016/j.foodqual.2012.10.009.

Ares, G. (2011). Non-sensory factors which influence choice behavior of foods that have a positive effect on health. In R. R. Watson, V. R. Preedy \& C. R. Martin (Eds.), Handbook of behavior food and nutrition (p. 757-770). New York: Springer.

Ares, G., Giménez, A., \& Deliza, R. (2010). Influence of three nonsensory factors on consumer choice of functional yogurts over regular ones. Food Quality and Preference, 21(4), 361-367. http:// dx.doi.org/10.1016/j.foodqual.2009.09.002.

Ares, G., Giménez, A., \& Gámbaro, A. (2009). Consumer perceived healthiness and willingness to try functional milk desserts. Influence of ingredient, ingredient name and health claim. Food Quality and Preference, 20(1), 50-56. http://dx.doi.org/10.1016/j. foodqual.2008.07.002.

Barreto, M. L. J., Rangel, A. H. N., Junior, S. M., Oliveira, J. P., \& Brito, A. S. (2012). Factores that influence the buying decision of consumers of milk Natal/RN. Revista Caatinga, 25(3), 118-124.

Bialkova, S., \& Van Trijp, H. (2010). What determines consumer attention to nutrition labels? Food Quality and Preference, 21(8), 1042-1051. http://dx.doi.org/10.1016/j.foodqual.2010.07.001.

Bouteille, R., Cordelle, S., Laval, C., Tournier, C., Lecanu, D. B., Hervé, E., \& Schlich, P. (2013). Sensory exploration of the freshness sensation in plain yoghurts and yoghurt-like products. Food Quality and Preference, 30(2), 282-292. http://dx.doi.org/10.1016/j.foodqual.2013.06.012.

Campbell, N., Correa-Rotter, R., Neal, B., \& Cappuccio, F. P. (2011). New evidence relating to the health impact of reducing salt intake. Nutrition, Metabolism, and Cardiovascular Diseases, 21(9), 617-619. http://dx.doi.org/10.1016/j.numecd.2011.08.001. PMid:21907903.

Carneiro, J. D. S., Minim, V. P. R., Deliza, R., Silva, C. H. O., Carneiro, J. C. S., \& Leão, F. P. (2005). Labelling effects on consumer intention to purchase for soybean oil. Food Quality and Preference, 16(3), 275282. http://dx.doi.org/10.1016/j.foodqual.2004.05.004.

Carrilo, E., \& Varela, P., \& Fiszman, S. (2012). Packaging information as a modulator of consumers' perception of enriched and reduced-calorie biscuits in tasting and non-tasting tests. Food Quality and Preference, 25(2), 105-115. http://dx.doi.org/10.1016/j.foodqual.2012.02.005.

Casey, M. A., \& Krueger, R. A. (1994). Focus group interviewing. In: Macfie H. J. H. \& Thomson D. M. H. (Eds.), Measurement of food 
preferences (chap. 4, pp. 77-96). Glasgow: Blackie Academic \& Professional.

Costell, E., Tarrega, A., \& Bayarri, S. (2010). Food acceptance. The role of consumer perception and attitudes. Chemosensory Perception, 3(1), 42-50. http://dx.doi.org/10.1007/s12078-009-9057-1.

Dantas, M. I. S., Deliza, R., Minim, V. P. R., \& Puschmann, R. (2004). The effect of packaging on the perception of minimally processed products. Journal of International Food \& Agribusiness Marketing, 16(2), 71-83.

Deliza, R., \& MacFie, H. J. H. (1996). The generation of sensory expectation by external cues and its effect on sensory perception and hedonic ratings: a review. Journal of Sensory Studies, 11(2), 103-128. http://dx.doi.org/10.1111/j.1745-459X.1996.tb00036.x.

Deliza, R., Macfie, H. J. H., \& Hedderley, D. (2003). Use of computer generated images and conjoint analysis to investigate sensory expectations. Journal of Sensory Studies, 18(6), 465-488. http:// dx.doi.org/10.1111/j.1745-459X.2003.tb00401.x.

Enneking, U., Neumann, C., \& Henneberg, S. (2007). How important intrinsic and extrinsic product attributes affect purchase decision. Food Quality and Preference, 18(1), 133-138. http://dx.doi.org/10.1016/j. foodqual.2005.09.008.

Gatti, E., Bordegoni, M., \& Spence, C. (2014). Investigating the influence of colour, weight, and fragrance intensity on the perception of liquid bath soap: An experimental study. Food Quality and Preference, 31, 56-64. http://dx.doi.org/10.1016/j.foodqual.2013.08.004.

Hailu, G., Boecker, A., Henson, S., \& Cranfield, J. (2009). Consumer valuation of functional foods and neutraceuticals in Canada. A conjoint study using probiotics. Appetite, 52(2), 257-265. http:// dx.doi.org/10.1016/j.appet.2008.10.002. PMid:19007828.

Hashim, I. B., Resurrecion, A. V. A., \& McWatters, K. H. (1996). Consumer Attitudes towards Irradiated Poultry. Food Technology, Chicago, 50(3), 77-80.

Jaeger, S. R. (2006). Non-sensory factors in sensory science research. Food Quality and Preference, 17(1-2), 132-144. http://dx.doi. org/10.1016/j.foodqual.2005.03.004.

Krause, A. J., Lopetcharat, K., \& Drake, M. A. (2007). Identification of the characteristics that drive consumer liking of butter. Journal of Dairy Science, 90(5), 2091-2102. http://dx.doi.org/10.3168/jds.2006823. PMid:17430906.

Lagerkvist, C. J. (2013). Consumer preferences for food labelling attributes: comparing direct ranking and best-worst scaling for measurement of attribute importance, preference intensity and attribute dominance. Food Quality and Preference, 29(2), 77-88. http://dx.doi.org/10.1016/j.foodqual.2013.02.005.

Lahne, J., \& Trubek, A. B. (2014). "A little information excites us." Consumer sensory experience of Vermont artisan cheese as active practice. Appetite, 78, 129-138. http://dx.doi.org/10.1016/j. appet.2014.03.022. PMid:24681405.

Lee, P. Y., Lusk, K., Mirosa, M., \& Oey, I. (2015). Effect of information on Chinese consumers' perceptions and purchase intention for beverages processed by high pressure processing, Pulsed-Electric
Field and Heat Treatment. Food Quality and Preference, 40, 16-23. http://dx.doi.org/10.1016/j.foodqual.2014.08.006.

McLean, R., Hoek, J., \& Hedderley, D. (2012). Effects of alternative label formats on choice of high- and low-sodium products in a New Zealand population sample. Public Health Nutrition, 15(5), 783-791. http://dx.doi.org/10.1017/S1368980011003508. PMid:22281127.

Moskowitz, H., \& Hartmann, J. (2008). Consumer research. Creating a solid base for innovative strategies. Trends in Food Science \& Technology, 19(11), 581-589. http://dx.doi.org/10.1016/j.tifs.2008.01.016.

Scot Consultoria. (2010). Aumenta o consumo de queijo no Brasil. Bebedouro: Scot Consultoria. Retrieved from https://www. scotconsultoria.com.br/leite/mercado-leite/161/aumenta-o-consumode- queijo-no-brasil.htm.

Siegrist, M., Sampfli, N., \& Kastenholz, H. (2008). Consumers' willingness to buy functional foods: the influence of carrier, benefit and trust. Appetite, 51(3), 526-529.

Soares, L. L. S., Deliza, R., \& Oliveira, S. P. (2008). The Brazilian consumer's understanding and perceptions of organic vegetables: a Focus Group approach. Food Science and Technology (Campinas.), 28(1), 241-246. http://dx.doi.org/10.1590/S0101-20612008000100034.

Torres-Moreno, M., Tarrega, A., Torrescasana, E., \& Blanch, C. (2012). Influence of label information on dark chocolate acceptability. Appetite, 58(2), 665-671. http://dx.doi.org/10.1016/j.appet.2011.12.005. PMid:22198318.

Tuorila, H., \& Cardello, A. V. (2002). Consumer responses to an off-flavor in juice in the presence of specific health claims. Food Quality and Preference, 13(7-8), 561-569. http://dx.doi.org/10.1016/ S0950-3293(01)00076-3.

Tuorila, H., \& Monteleone, E. (2009). Sensory food science in the changing society. Opportunities needs and challenges. Trends in Food Science \& Technology, 20(2), 54-62. http://dx.doi.org/10.1016/j. tifs.2008.10.007.

Urala, N., \& Lähteenmäki, L. (2003). Reasons behind consumers' functional food choices. Nutrition \& Food Science, 33(4), 148-158. http://dx.doi.org/10.1108/00346650310488499.

Urala, N., \& Lähteenmäki, L. (2007). Consumers' changing attitudes towards functional foods. Food Quality and Preference, 18(1), 1-12. http://dx.doi.org/10.1016/j.foodqual.2005.06.007.

van Kleef, E., van Trijp, H. C. M., \& Luning, P. (2005). Consumer research in the early stages of new product development: a critical review of methods and techniques. Food Quality and Preference, 16(3), 181-201. http://dx.doi.org/10.1016/j.foodqual.2004.05.012.

van Trijp, H. C. M., \& van Der Lans, I. A. (2007). Consumer perceptions of nutrition and health claims. Appetite, 48(3), 305-324. http://dx.doi. org/10.1016/j.appet.2006.09.011. PMid:17157958.

Verbeke, W. (2006). Functional foods: consumer willingness to compromise on taste for health. Food Quality and Preference, 17(1-2), 126-131. http://dx.doi.org/10.1016/j.foodqual.2005.03.003.

Wyness, L. A., Butriss, J. L., \& Stanner, S. A. (2012). Reducing the population's sodium intake. The UK Food Standards Agency's salt reduction programme. Public Health Nutrition, 15(2), 254-261. http://dx.doi.org/10.1017/S1368980011000966. PMid:21729460. 